\title{
Catalytic Hydroxylation in Biphasic Systems using
}

CYP102A1 Mutants

Steffen C. Maurer, ${ }^{[\mathrm{a}]}$ Katja Kühnel, ${ }^{\left[{ }^{[a]}\right.}$ Leonard A. Kaysser, ${ }^{[\mathrm{a}]}$ Sabine Eiben, ${ }^{[\mathrm{a}]}$ Rolf D. Schmid ${ }^{[\mathrm{ad}]}$ and Vlada B. Urlacher ${ }^{*[\mathrm{a}]}$

[a] Institute of Technical Biochemistry, Stuttgart University, Allmandring 31, 70569 Stuttgart, Germany

Fax: +49 711-685-3196

E-mail: itbvur@itb.uni-stuttgart.de 


\section{Abstract}

Cytochrome P450 monooxygenases are biocatalysts that hydroxylate or epoxidise a wide range of hydrophobic organic substrates. To date their technical application is limited to a small number of whole-cell biooxidations. The use of the isolated enzymes is believed to be impractical due to the low stability of this enzyme class, to the stochiometric need of the expensive cofactor NADPH, and due to the low solubility of most substrates in aqueous media. To overcome these problems we have investigated the application of a bacterial monooxygenase (mutants of CYP102A1) in a biphasic reaction system supported by cofactor recycling with $\mathrm{NADP}^{+}$-dependent formate dehydrogenase from Pseudomonas sp 101. Using this experimental setup, cyclohexane, octane and myristic acid were hydroxylated. To reduce the process costs a novel NADH-dependent double mutant of CYP102A1 was designed. For recycling of NADH during myristic acid hydroxylation in a biphasic system NAD+-dependent FDH was used.

Stability of the monooxygenase under the reaction conditions is quite high as revealed by total turnover numbers of up to 12850 in NADPH-dependent cyclohexane hydroxylation and up to 30000 in NADH-dependent myristic acid oxidation.

\section{Keywords}

biotransformation, biphasic system, cofactor recycling, cofactor specificity, hydroxylation, green chemistry, P450 monooxygenase

\section{Introduction}

Cytochromes P450 belong to the heme-containing enzyme class of monooxygenases (EC 1.14.x.y). They are widely distributed in nature and play an important role in primary and secondary metabolism as well as in detoxification of xenobiotic compounds. ${ }^{[1]}$

P450 enzymes catalyse the transfer of molecular oxygen to even non-activated aliphatic or aromatic $\mathrm{XH}$-bonds $(\mathrm{X}:-\mathrm{C},-\mathrm{N},-\mathrm{S})$. Moreover, a remarkable number of $\mathrm{P} 450$ enzymes are capable of epoxidising $\mathrm{C}=\mathrm{C}$-double bonds. ${ }^{[2]}$ Common to both 
reaction types is the incorporation of one atom of dioxygen into the substrate, while the other atom is reduced to water by electrons ultimately originating from the nicotinamide cofactors $\mathrm{NAD}(\mathrm{P}) \mathrm{H}$. Electrons are transferred from $\mathrm{NAD}(\mathrm{P}) \mathrm{H}$ to the P450 heme iron via a flavin reductase or / and an iron-sulphur-protein. ${ }^{[3]}$

Currently oxygenases are mainly applied in whole-cell biotransformations. ${ }^{[4,5]}$ Whole cells stabilise the complex enzyme systems with up to three individual proteins and simultaneously regenerate cofactors based on the cellular metabolism. Disadvantages of whole-cell processes might be a further metabolism of products, toxicity of the educts or products to the cell, and the recovery of products from a complex fermentation broth. Considering these problems, the use of isolated oxygenases in enzyme reactors could be advantageous. ${ }^{[6-9]}$ Regarding the application of isolated P450 monooxygenases in fine chemical synthesis, enzymes from bacterial sources turned out as more suitable than those originating from plants, fungi or vertebrates: besides a much higher activity compared to eucaryotic enzymes, bacterial P450s exhibit in many cases higher stability. ${ }^{[10]}$

P450 enzymes consisting of a heme domain fused to an FAD- and FMN-containing P450 reductase domain are - in contrast to the majority of P450s - "self-sufficient", i.e., they do not have to be supplied with additional redox partners (reductases) apart from NADPH. The best characterised fusion protein CYP102A1 (also called CYP102A1) from Bacillus megaterium has been intensively studied during the last two decades. ${ }^{[11,12]}$ This enzyme converts saturated- and unsaturated fatty acids with chain length of C12 to C22 with high activity (up to $4000 \mathrm{~min}^{-1}$ ) and partially also high stereoselectivity to their subterminally oxygenated derivatives. ${ }^{[13,14]}$ Recently cloning and characterisation of two further fusion enzymes from Bacillus subtilis, which exhibit high homology to CYP102A1, was reported. ${ }^{[15-17]}$ While a large number of publications describing novel evolved CYP102A1 mutants with altered substrate specificity exist, ${ }^{[18-26]}$ there are only very few reports dealing with the use of these biocatalysts in preparative organic synthesis. ${ }^{[7,27]}$ Beside strong doubts concerning the operational stability of the enzyme class, the high cost of the nicotinamide cofactor NADPH which has to be added in stochiometric or even higher amount (if uncoupling is taken into account) seems to make their in vitro application impractical. Several possibilities exist to circumvent the stochiometric need for cofactors, for example, the use of peroxides (so-called shunt-pathway) ${ }^{[28]}$ or cathodic reduction of the heme iron. ${ }^{\text {[29-31] }}$ 
Reduction of the oxidised cofactor $\operatorname{NAD}(P)^{+}$during biotransformations can be performed electrochemically via mediators ${ }^{[32]}$ or enzymatically. Dehydrogenases are currently utilised for cofactor recycling in various biocatalytic processes. ${ }^{[7,33,34]}$ In a previous paper we reported a cofactor recycling system for CYP102A1 by mean of an $\mathrm{NADP}^{+}$-dependent formate dehydrogenase (FDH, EC 1.2.1.2) from Pseudomonas $s p$ 101. It has been shown that both enzymes can be used for synthesis in combination. ${ }^{[34]}$

Using this approach we have developed a process for oxidation of cyclohexane in a biphasic (cyclohexane / aqueous buffer) system. Industrial oxidation of cyclohexane is a process still open to improvements. Thus on one hand this reaction serves as a model reaction for activation of an inert hydrocarbon, on the other hand there might be interest in an alternative approach.

In order to proof the general applicability of CYP102A1 mutants in two-phase reaction systems, hydroxylation of octane and myristic acid was investigated.

Further reduction of the process costs was achieved by switching the cofactor specificity of CYP102A1 from NADPH to NADH. The advantage of NADH is its lower price and higher stability ${ }^{[47]}$ Besides that $N A D^{+}$-dependent dehydrogenases are more abundant in nature than their $\mathrm{NADP}^{+}$-dependent analogues, opening the possibility to combine CYP102A1-catalysed reactions with a large variety of dehydrogenases.

\section{Results and Discussion}

\section{Identification of CYP102A1 Mutants Hydroxylating Cyclohexane}

A set of CYP102A1 mutants constructed by site-directed mutagenesis was screened for activity towards cyclohexane by monitoring of NADPH turnover et $340 \mathrm{~nm}$ during the hydroxylation reaction. The results are summarised in Figure 1. 


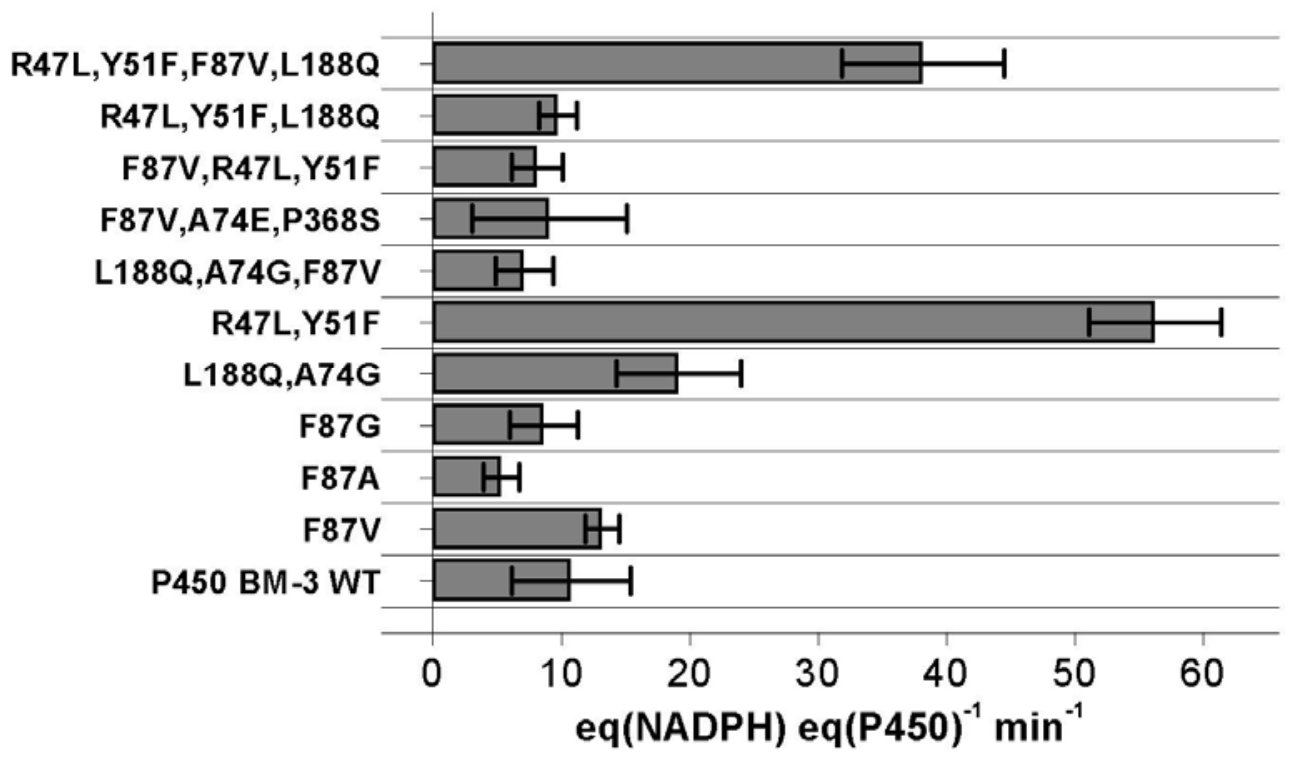

Figure 1. Results of screening a CYP102A1 mutant library for activity towards cyclohexane. NADPH consumption in presence of $470 \mu \mathrm{M}$ cyclohexane was tracked for 3 minutes to yield values which are, in contrast to initial reaction rates, valid for extended periods of time.

Highest activity (56 eq eq ${ }^{-1} \mathrm{~min}^{-1}$ ) was detected for the CYP102A1 mutant R47L, Y51F. Both amino acid substitutions render the substrate access channel more hydrophobic causing easier access of cyclohexane to the active centre of the enzyme. ${ }^{[35-37]}$ The mutant R47L, Y51F, F87V, L188Q with enlarged binding pocket ${ }^{[38]}$ also showed rather high activity of $38 \mathrm{eq} \mathrm{eq}^{-1} \mathrm{~min}^{-1}$, however not reaching the double mutant's activity.

Uncoupling of NADPH oxidation and substrate hydroxylation resulting in reduction of oxygen to hydrogen peroxide or water is an issue frequently encountered in monooxygenase chemistry. ${ }^{[39,40]}$ Therefore product formation and its coupling to NADPH consumption was investigated by GC/MS analysis (data not shown). This revealed coupling efficiencies of $25 \%$ for R47L, Y51F , 19\% for R47L, Y51F, F87V, L188Q and $16 \%$ for A74G, L188Q and only $6 \%$ for wild type CYP102A1. All mutants for which coupling efficiency was measured, produced cyclohexanol as single product (GC/MS data not shown). As the double mutant R47L, Y51F was revealed as the most active cyclohexane-hydroxylase (cyclohexane hydroxylation activity: $14 \mathrm{~min}^{-}$ 1 for R47L, Y51F compared to $0.75 \mathrm{~min}^{-1}$ for the wild type enzyme) among the mutants investigated, it was used in further experiments. 


\section{Kinetic Characterisation}

Kinetic data for the purified mutant R47L, Y51F were determined by monitoring of cyclohexane-dependent NADPH-oxidation at a saturating concentration of the cofactor.

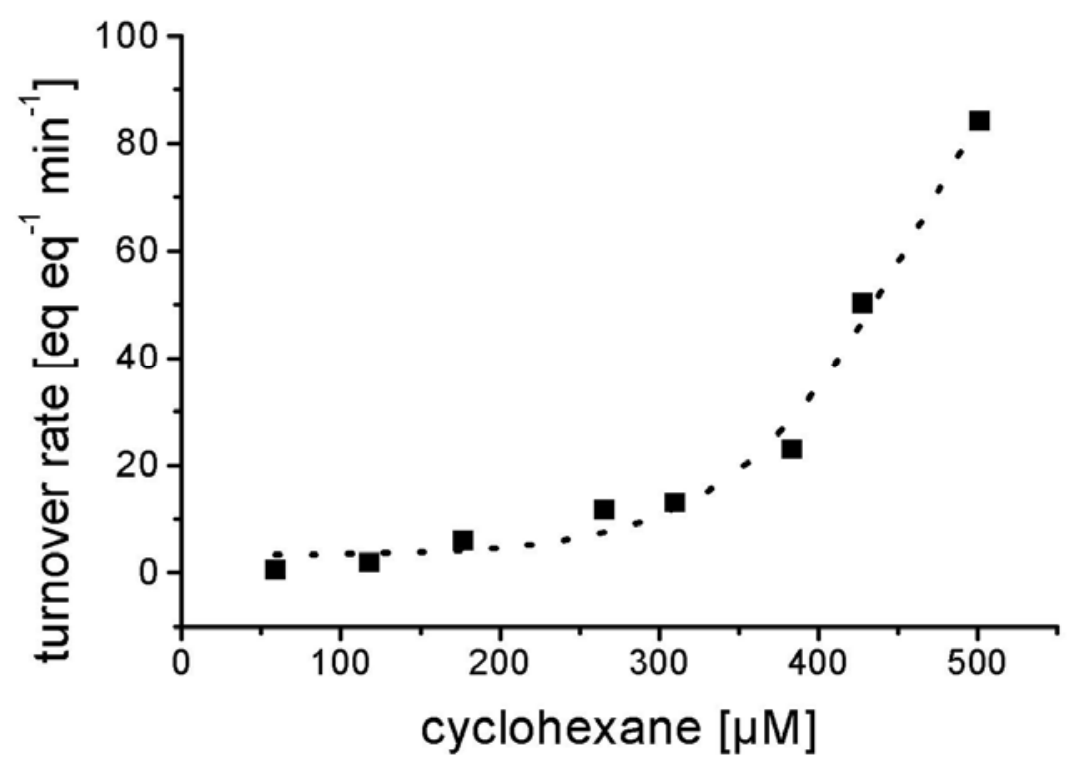

Figure 2. Steady-state NADPH turnover rates at various cyclohexane concentrations for purified CYP102A1 mutant R47L, Y51F. The plot indicates sigmoidal dependency of the reaction rate on substrate concentration. This clearly indicates non-Michaelis-Menten kinetics.

The plot of NADPH oxidation rate versus cyclohexane concentration shown in Figure 2 demonstrates nonhyperbolic characteristics. This indicates cooperativity in substrate binding according to the Hill kinetic model. Even at the maximum cyclohexane concentration $(\approx 500 \mu \mathrm{M})$ limited by its solubility in the aqueous phase, saturation of the active centre of the enzyme was not reached.

Substrate binding to P450 usually causes a heme spin-state shift from low to high, which can be monitored as changes in P450 absorbance spectra (Figure 3). Cyclohexane binds to R47L, Y51F leading to an increase in the difference between the absorbance at $417 \mathrm{~nm}$ (trough) and that at $387 \mathrm{~nm}$ (peak). However, the maximum heme spin-state shift was not reached at a concentration of cyclohexane of $500 \mu \mathrm{M}$, corresponding to full saturation of the active centre in aqueous milieu.

The plot of absorption differences at $\sim 387 \mathrm{~nm}$ and $417 \mathrm{~nm}$ versus cyclohexane concentration indicates exponential growth of the spectral changes in the concentration range limited by the solubility limit (small graph in Figure 3). 


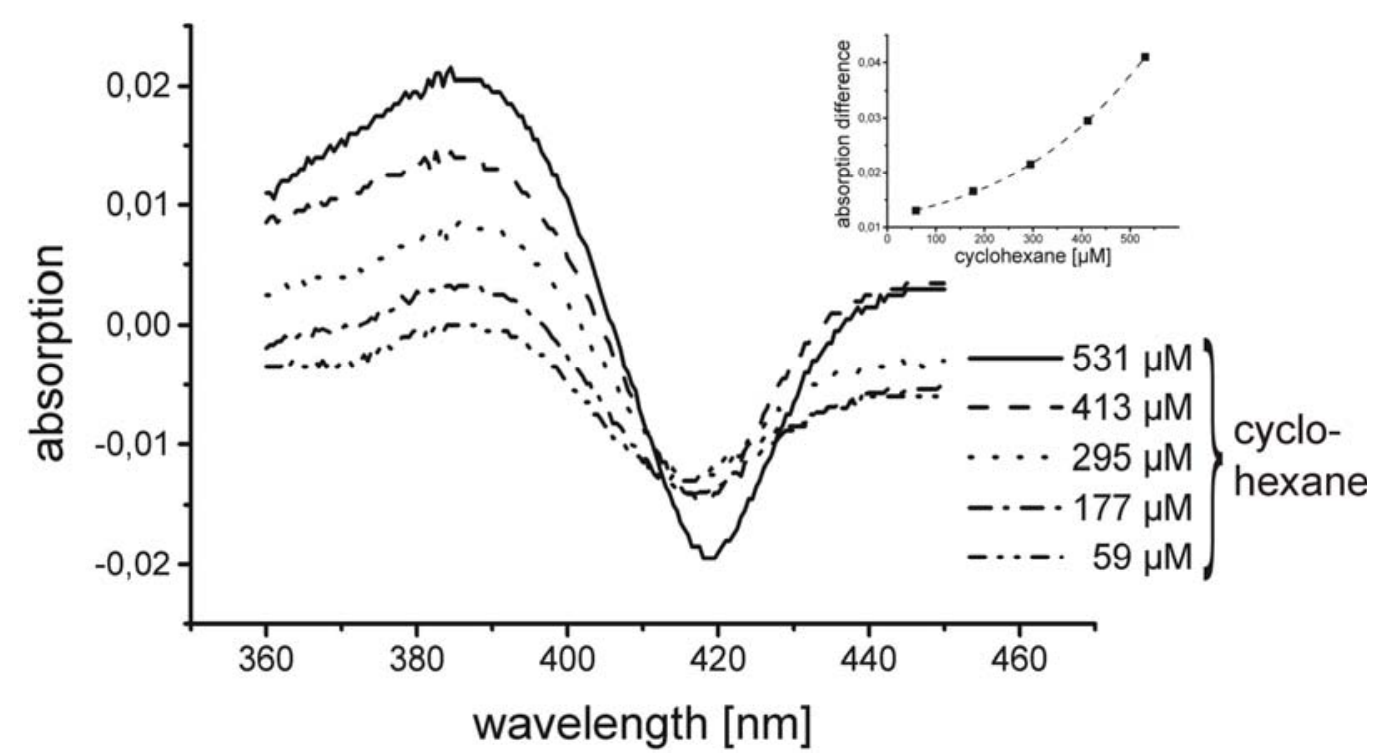

Figure 3. Cyclohexane binding difference spectra of CYP102A1 R47L, Y51F. Difference spectra were obtained by subtracting reference spectra of enzyme $(8.6 \mu \mathrm{M})$ without substrate from spectra of samples containing the indicated cyclohexane concentrations and exactly the same enzyme concentration as the reference. The small chart at the right upper corner was generated by plotting $A_{387}$ minus $A_{417}$ data from the difference spectra versus the relevant cyclohexane concentrations.

These measurements confirm the steady-state kinetic data. This is, however, atypical for CYP102A1 that usually corresponds to Michaelis-Menten kinetics.

The results summarised in figures 2 and 3 clearly demonstrate that application of CYP102A1 mutant R47L, Y51F would benefit from increased cyclohexane concentration in the aqueous phase. Different detergents as Tween 20, Tween 80, cholate, CHAPS, $\alpha$-cyclodextrine, $\beta$-cyclodextrine and co-solvents as methanol, ethanol, DMSO, acetone, butanol, THF were tested with CYP102A1 R47L, Y51F in aqueous milieu. Only Tween 20 and 80 displayed a positive effect expressing in 1.5and 2-fold cyclohexane hydroxylation activity when applied at $1 \%$ (v/v). However, these beneficial effects could not be transferred to the two-phase reaction system. While Tween enhanced activity of the monooxygenase by increasing the cyclohexane concentration, the stability of monooxygenase and / or dehydrogenase was negatively affected. 


\section{Biphasic Reaction System Cyclohexane I Aqueous Buffer}

We investigated the optimal conditions for hydroxylation of cyclohexane by CYP102A1 in a biphasic reaction system (Figure 4). In this system cyclohexane acts as substrate pool and simultaneously as organic solvent for extraction of the reaction product. Thus the catalytic system is retained in the aqueous phase while the product may continuously be isolated from the organic phase. The cofactor recycling system is based on a mutant of FDH from Pseudomonas sp which has been proven as highly stable in organic solvents. ${ }^{[8,41]}$

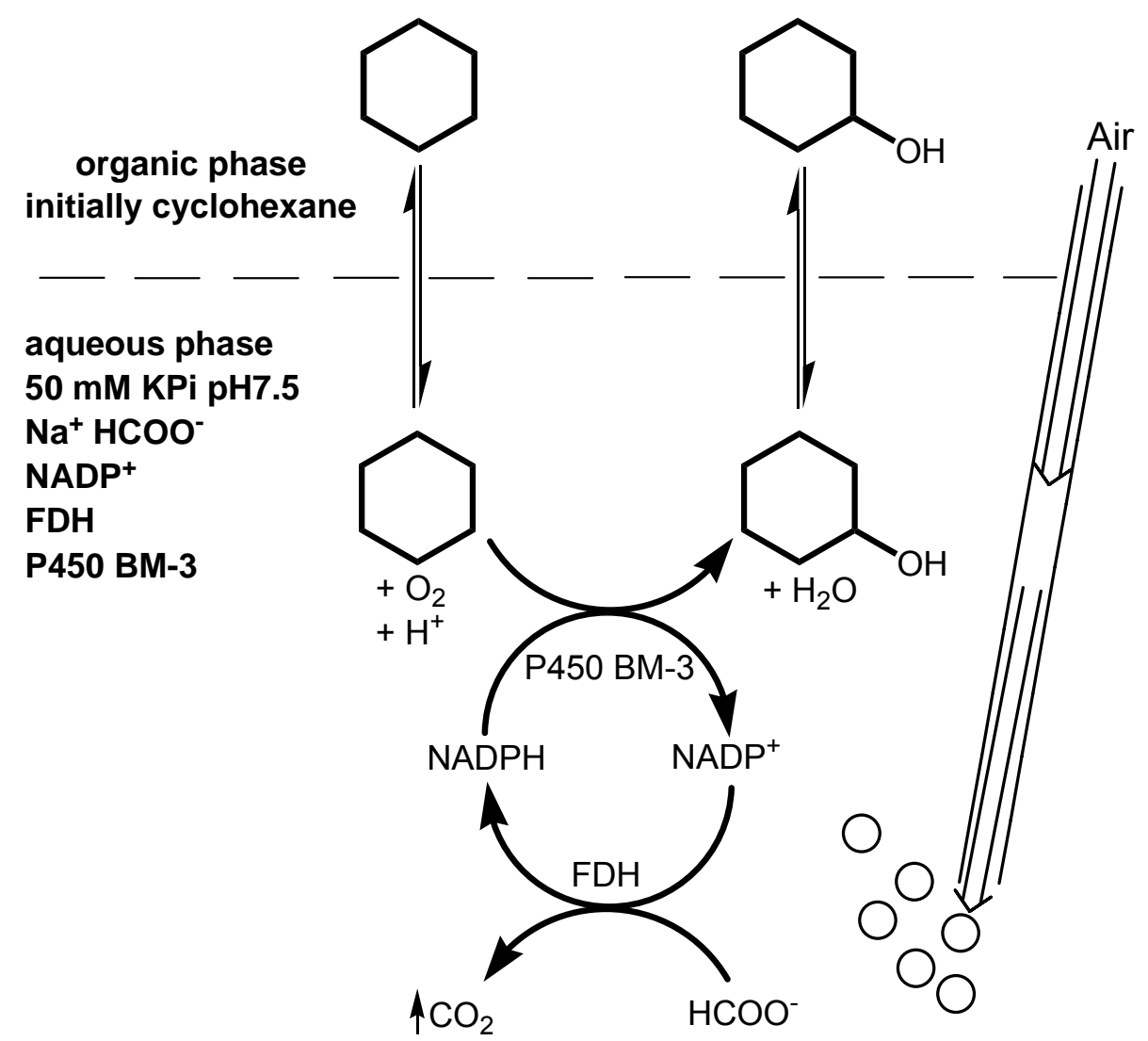

Figure 4. Scheme for CYP102A1-mediated hydroxylation of cyclohexane in a two-phase system. The organic phase serves as substrate pool and extracts the products from the aqueous phase.

The stability of this dehydrogenase in a 1:1 mixture of FDH reaction buffer and cyclohexane under vigorous stirring was tested. FDH activity assays revealed a halflife of at least one day for this cofactor regenerating enzyme in the two-phase system.

The effect of different protein stabilisation agents - glycerol, bovine serum albumin (BSA), catalase, PEG-derivatives - was studied. Addition of $10 \mathrm{mg} \mathrm{ml}^{-1} \mathrm{BSA}$ and 0.2 
$\mathrm{mg} \mathrm{ml}^{-1}$ (600 $\mathrm{U} \mathrm{ml}^{-1}$ ) catalase from horse liver stabilised the monooxygenases in the biphasic emulsion and led to higher activity for extended periods of time, resulting in an increase in product yield (data not shown).

Concentration of cyclohexanol in the organic phase measured during the biotransformation indicates that mutant R47L, Y51F was active for at least four days ( $100 \mathrm{~h})$ when stabilised by addition of BSA and catalase (Figure 5).

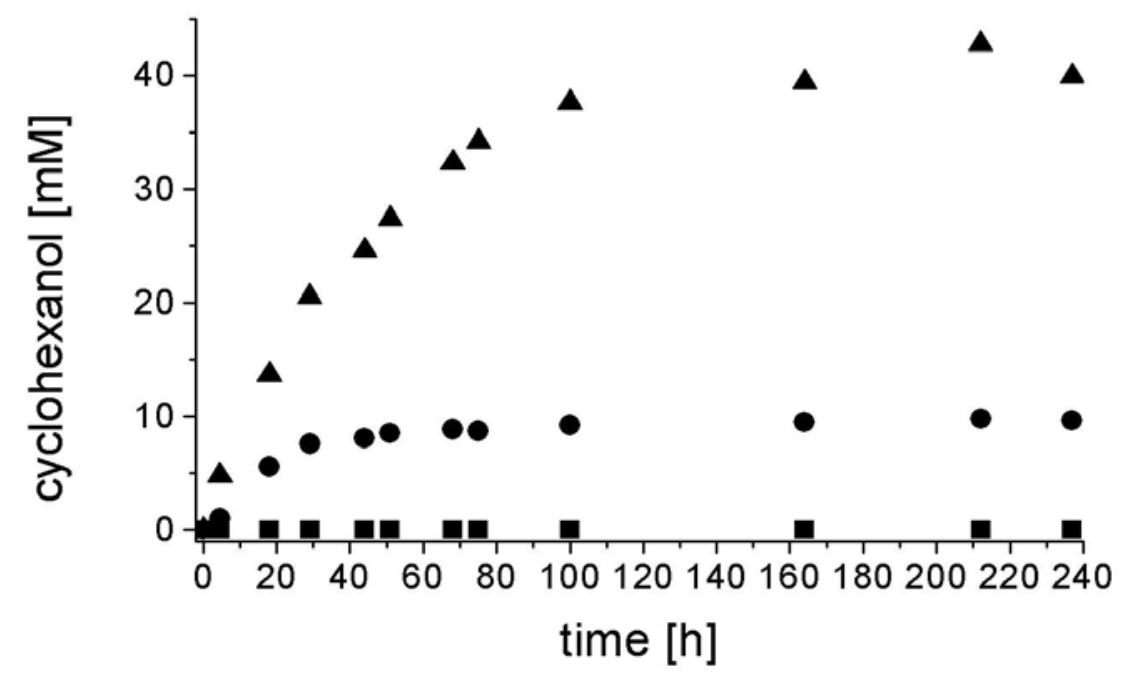

Figure 5. Production of cyclohexanol during reaction in the biphasic system. Reaction in stirred $20 \mathrm{ml}$ flask containing $5 \mathrm{ml}$ cyclohexane and $5 \mathrm{ml}$ aqueous reaction medium. Squares: Negative control containing E.coli cell extract; circles: CYP102A1 mutant A74G, F87V, L188Q ; triangles: CYP102A1 mutant R47L, Y51F.

Limitations in transfer of substrate from the organic to the aqueous phase decrease reaction rates, at least if phase transfer is slower than the rate of hydroxylation.

This was not the case here, as can be concluded from Figure 5. The triple mutant displayed a lower reaction rate than the double mutant (Figure 1, $7 \mathrm{eq} \mathrm{eq}^{-1} \mathrm{~min}^{-1}$ compared to $56 \mathrm{eq} \mathrm{eq}^{-1} \mathrm{~min}^{-1}$ respectively) also showed lower cyclohexanol production in the biphasic reaction system. For the best mutant R47L, Y51F the total turnover number (ttn) was 9620. An increase in ttn to 10280 was achieved by changing the reaction vessel from a stirred flask at RT to a shaking flask vigorously shaken at $160 \mathrm{rpm}$ and $18^{\circ} \mathrm{C}$.

In a further experiment, the reaction system was scaled up to one litre reaction volume $(1.3 \mu \mathrm{mol}$ of CYP102A1 R47L, Y51F) under continuous aeration. The on-line monitoring of oxygen partial pressure and $\mathrm{pH}$ allow to control the reaction progress. 
As protons are stochiometrically consumed during the reaction (Figure 4), the $\mathrm{pH}$ value increases. The $\mathrm{pH}$ was readjusted daily using $1 \mathrm{M} \mathrm{KPi} \mathrm{pH} \mathrm{6.0.} \mathrm{The} \mathrm{subsequent}$ loss in activity can - apart from the decrease in product development - be concluded from the increase in oxygen partial pressure (oxygen consumption by the hydroxylation reaction breaks down) and from the slower increase in $\mathrm{pH}$.

The total turnover number in this system reached 12850 , yielding $1.67 \mathrm{~g}$ of cyclohexanol $(16.7 \mathrm{mmol})$. The course of product development indicates that the monooxygenase was active for at least $100 \mathrm{~h}$. During the first $53 \mathrm{~h}$ productivity of the system (12.62 mmol cyclohexanol) was higher than during the second half of the reaction. Space-time yield during the first $53 \mathrm{~h}$ of reaction time amounts $23.8 \mathrm{mg} \mathrm{l}^{-1} \mathrm{~h}^{-}$ 1. This result can be exceeded to the limit posed by the rate of substrate transfer to the aqueous phase by applying higher concentrations of CYP102A1 and FDH.

\section{Conversion of Octane and Myristic Acid}

In order to demonstrate the general applicability of the biphasic system, octane and myristic acid - both substrates of CYP102A1 mutant A74G, F87V, L188Q with turnover rates of $1760 \mathrm{nmol}(\mathrm{NADPH}) \mathrm{nmol}(\mathrm{P} 450)^{-1} \mathrm{~min}^{-1}\left[{ }^{[19]}\right.$ and $2100 \mathrm{nmol}(\mathrm{NADPH})^{-}$ ${ }^{1} \mathrm{nmol}(\mathrm{P} 450)^{-1} \mathrm{~min}^{-1}$, respectively - were also investigated.

Similar to the experiments with cyclohexane octane was used as substrate and as organic phase. GC/MS analysis revealed a product mixture consisting of 2-, 3- and 4octanol as well as the corresponding octanones. Formation of octanones by CYP102A1 was previously reported. ${ }^{[20]} \mathrm{A}$ possible mechanism for the formation of the ketones is a second hydroxylation of the alcohol to generate a gem-diol which dehydrates to the corresponding ketone. Ketones might alternatively originate from vic-diols via Pinakol rearrangement. In any case double hydroxylation is a prerequisite for ketone formation. For calculation of total turnover numbers the GC/MS signals of all reaction products were calibrated for quantification using authentic standards of known concentration. For octane hydroxylation ttn of 2200 was measured.

For hydroxylation of myristic acid in the biphasic system, the substrate was dissolved in dodecane. In preliminary investigations dodecane was proven not to be a substrate of CYP102A1 A74G, F87V, L188Q. Fatty acid hydroxylation was performed 
under constant air bubbling. Total reaction volume was $8 \mathrm{ml}$ consisting of $4 \mathrm{ml}$ of the aqueous catalyst system and $4 \mathrm{ml} 100 \mathrm{mM}$ myristic acid (91 mg) in dodecane.

With myristic acid as a substrate for CYP102A1, usually a mixture of the subterminally hydroxylated products is obtained. ${ }^{[13,14]}$ In the two-phase system, however, additionally to the monohydroxylated products dihydroxylated myristic acid derivatives were produced. A hydroxylation of 12-hydroxy and 13-hydroxy myristic acid has previously been reported, even though with low reaction rate. ${ }^{[42]}$ Totally 92.9 $\mathrm{mg}$ of myristic acid and derivatives were extracted. This amount of substance consisted of $41.4 \mathrm{mg}$ of myristic acid (predominantly found in the dodecane-phase) and of $51.5 \mathrm{mg}$ (55\%) of hydroxylated products less soluble in dodecane. Hydroxylated products consisted of $48 \%$ monohydroxy ( $\omega-1$ to $\omega-7)$ and $52 \%$ dihydroxy myristic acid (mixture of 7 regioisomers). As stated in Table 2 this corresponds to ttns of 3300 for the P450 enzyme and 825 for the cofactor NADP'.

These results clearly indicate the applicability of the biphasic reaction system for conversion of different substrates of CYP102A1. In contrast to cyclohexane hydroxylation, in case of octane and myristic acid, the selectivity of the P450 biocatalysts remains to be improved.

\section{Conversion of Myristic Acid by an NADH-dependent CYP102A1 Mutant}

Multiple sequence alignment of NADPH-dependent cytochrome P450 reductases, which supply the P450 monooxygenases with electrons, revealed 5 highly conserved positions important for cofactor specificity. ${ }^{[48,49]}$ These positions in CYP102A1 are S965, R966, K972 and Y974, which bind the 2'-phosphate group of NADPH and W1046, the so-called gate-keeping amino acid, involved in electron transfer. Döhr et al. changed the cofactor specificity of the human P450 reductase from NADPH to $\mathrm{NADH}$ via substitution of the gate-keeping tryptophan to alanine. ${ }^{[49]}$

The same effect was observed for the CYP102A1 mutant W1046A, that could accept $\mathrm{NADH}$ as cofactor $\left(\mathrm{K}_{\mathrm{M}}(\mathrm{NADH})=14 \mu \mathrm{M}\right.$ and $\mathrm{k}_{\text {cat }}(\mathrm{NADH})=6300 \mathrm{~min}^{-1}$ compared to BM-3 wild type reductase: $\mathrm{K}_{\mathrm{M}}(\mathrm{NADPH})=2.5 \mu \mathrm{M}, \mathrm{K}_{\text {cat }}(\mathrm{NADPH})=7930 \mathrm{~min}^{-1}, \mathrm{~K}_{\mathrm{M}}$ $(\mathrm{NADH})=1430 \mu \mathrm{M}$ and $\left.k_{\text {cat }}(\mathrm{NADH})=2810 \mathrm{~min}^{-1}\right)$ as revealed by reduction of cytochrome $\mathrm{c}$. However in our investigation serine at this position caused a stronger effect on the switch in cofactor specificity $\left(K_{M}(N A D H)=4.4 \mu \mathrm{M}\right.$ und $k_{\text {cat }}(N A D H)=$ $\left.4710 \mathrm{~min}^{-1}\right)$. A further improvement in terms of catalytic activity of the CYP102A1 
reductase with $\mathrm{NADH}$ was achieved by substitution of the phosphate binding arginine 966 by aspartate. Kinetic constants for the reductase double mutant R966D, W1046S were $\mathrm{K}_{\mathrm{M}}(\mathrm{NADH})=12 \mu \mathrm{M}, \mathrm{k}_{\mathrm{cat}}(\mathrm{NADH})=14601 \mathrm{~min}^{-1}$. Thus the catalytic efficiency $\left(\mathrm{k}_{\text {cat }} / \mathrm{K}_{\mathrm{M}}\right)$ of the CYP102A1 reductase in NADH-dependent cytochrome $\mathrm{C}$ reduction was improved 640-fold. Further details on reductase mutants will be described elsewhere. ${ }^{[52]}$

Table 1: Comparison of $\mathrm{K}_{\mathrm{M}^{-}}$and $\mathrm{k}_{\mathrm{cat}}$-values for reductase mutants. Values were determined by NADPH- or NADH-dependent cytochrome $\mathrm{C}$ reduction assay, respectively. The monooxygenase domain in all cases carried mutations A74G, F87V, L188Q.

\begin{tabular}{|c|c|c|c|c|}
\hline & WT-reductase & W1046A & W1046S & $\begin{array}{l}\text { R966D, } \\
\text { W1046S }\end{array}$ \\
\hline $\mathrm{K}_{\mathrm{M}}(\mathrm{NADPH})$ & $(2.5 \pm 0.2) \mu \mathrm{M}$ & $\begin{array}{l}(0.82 \pm 0.08) \\
\mu \mathrm{M}\end{array}$ & $\begin{array}{l}(0.78 \pm 0.05) \\
\mu \mathrm{M}\end{array}$ & $(1.6 \pm 0.2) \mu \mathrm{M}$ \\
\hline $\mathrm{k}_{\mathrm{cat}}(\mathrm{NADPH})$ & $\begin{array}{l}\left(\begin{array}{l}7930 \\
\min ^{-1}\end{array}\right. \\
\end{array}$ & $(524 \pm 5) \mathrm{min}^{-1}$ & $(366 \pm 4) \min ^{-1}$ & $\begin{array}{l}(5410 \pm 430) \\
\min ^{-1}\end{array}$ \\
\hline $\mathrm{K}_{\mathrm{M}}(\mathrm{NADH})$ & $(1430 \pm 70) \mu \mathrm{M}$ & $\begin{array}{l}(14.0 \pm 0.75) \\
\mu \mathrm{M}\end{array}$ & $(4.4 \pm 0.1) \mu \mathrm{M}$ & $(11.6 \pm 0.7) \mu \mathrm{M}$ \\
\hline $\mathrm{k}_{\text {cat }}(\mathrm{NADH})$ & $\begin{array}{l}(2810 \pm 100) \\
\min ^{-1}\end{array}$ & $\begin{array}{l}(6300 \pm 100) \\
\min ^{-1}\end{array}$ & $\begin{array}{l}(4710 \pm 40) \\
\min ^{-1}\end{array}$ & $\begin{array}{l}(14600 \pm 1200) \\
\min ^{-1}\end{array}$ \\
\hline
\end{tabular}

The CYP102A1 reductase double mutant R966D, W1046S was fused to the CYP102A1 A74G, F87V, L188Q monooxygenase domain.To proof applicability of this NADH-dependent CYP102A1 mutant in organic synthesis, oxidation of myristic acid was performed in the two-phase reaction system described above for the $\mathrm{NADPH}$-dependent variant, except that $\mathrm{NADP}^{+}$-dependent $\mathrm{FDH}$ and $\mathrm{NADP}^{+}$were exchanged by $\mathrm{NAD}^{+}$-dependent $\mathrm{FDH}^{[46]}$ and $\mathrm{NAD}^{+}$. Extraction of the reaction mixture and subsequent GC/MS analysis revealed $20 \%$ conversion to hydroxylated products. The hydroxy- and dihydroxy myristic acid products identified were the same as in the NADPH-driven reaction. Again, about $50 \%$ of the products were identified as dihydroxy myristic acid derivatives. The lower yield of products (20\% compared to 55 $\%$ yield in the NADPH-dependent reaction) is most likely a result of the lower amount of P450 enzyme added to the reaction mixture ( $5 \mathrm{nmol}$ compared to $100 \mathrm{nmol}$ ). 
Though the NADPH-dependent myristic acid hydroxylation seems to be limited by the substrate's phase transfer rate, while the NADH-dependent reaction is limited by the amount of enzyme used. In conclusion activity and stability of NADH- and NADPHdependent CYP102A1 are comparable. In this experiment the th reached 30000 , to the knowledge of the authors the highest value reported for a P450 monooxygenase to date (Table 2). Further experiments on use of the NADH-dependent system in preparative organic synthesis are currently being performed.

Table 2: Comparison of the biotransformation reactions in biphasic reaction media.

\begin{tabular}{|c|c|c|c|c|c|c|c|}
\hline Substrate & CYP102A1 mutant & $\begin{array}{c}\text { Reaction } \\
\text { time }[\mathrm{h}]\end{array}$ & $\begin{array}{c}\text { Reaction } \\
\text { volume } \\
{[\mathrm{ml}]}\end{array}$ & $\begin{array}{c}\text { Amount of } \\
\text { CYP102A1 } \\
{[\mathrm{nmol}]}\end{array}$ & $\begin{array}{c}\text { ttn for } \\
\text { CYP102A1 } \\
\text { mutant }\end{array}$ & $\begin{array}{c}\text { ttn for } \\
\text { cofactor } \\
\text { NAD(P) })^{+\mathrm{a}}\end{array}$ & $\begin{array}{c}\text { Volumetric } \\
\text { productivity } \\
\left(\mathrm{mg} \mathrm{l}^{-1} \mathrm{~h}^{-1}\right)^{\mathrm{b}}\end{array}$ \\
\hline Cyclohexane & R47L,Y51F & 100 & $\begin{array}{c}10 \text { (stirred } \\
\text { flask) } \\
10 \text { (stirred } \\
\text { flask) }\end{array}$ & 66 & 9620 & 1270 & 63.5 \\
Cyclohexane & A74G,F87V,L188Q & 100 & 100 & $\begin{array}{c}40 \text { (shaking } \\
\text { flask) } \\
1000\end{array}$ \\
Cyclohexane \\
Octane
\end{tabular}




\begin{tabular}{|c|c|c|c|c|c|c|c|}
\hline acid & A74G,F87V,L188Q & 80 & flask) & 100 & 3300 & 825 & 101 \\
\hline $\begin{array}{c}\text { Myristic } \\
\text { acid }\end{array}$ & $\begin{array}{l}\text { A74G,F87V,L188Q, } \\
\text { R966D, W1046S } \\
\text { (NADH-dependent) }\end{array}$ & 24 & $\begin{array}{c}10 \text { (stirred } \\
\text { flask) }\end{array}$ & 5 & 30000 & 300 & 153 \\
\hline
\end{tabular}

${ }^{\mathrm{a}} \mathrm{NAD}(\mathrm{P}) \mathrm{H}$ concentration was $0.1 \mathrm{mM}$ in the aqueous phase.

${ }^{\mathrm{b}}$ calculated for the whole reaction time. Higher volumetric activities can be calculated for the beginning of the reactions.

\section{Conclusions}

The exploitation of isolated P450 monooxygenases in biocatalysis is a field of ongoing research. However, until now it is not certain if the properties of these enzymes allow their in vitro use. Although a few reports concerning the use of oxygenases (for a compilation see ${ }^{[53]}$ ) in synthetic applications do exist, bioengineering-related data are still scarce.

We thus investigated hydroxylation of substrates of CYP102A1 in a biphasic system. In order to facilitate catalyst preparation cell extracts were used without further processing. Due to the high expression level of the biocatalyst $(\sim 1 \mu \mathrm{mol}$ per litre fermentation broth) in recombinant E. coli, this represents an economically attractive approach. The proposed biphasic reaction scheme (Figure 4) is especially fitted to the requirements of the catalytic system under debate: The aqueous phase dissolves - and retains - cofactor and proteins without need for expensive membrane technology. The organic phase acts as substrate pool dissolving substrates or representing the substrate itself. Also a substantial amount of reaction products accumulates in the organic phase. These can be continuously removed using extraction, distillation or adsorption to resins.

Our experiments (Table 2) can be compared to the first report of preparative in vitro use of a bacterial P450 monooxygenase by Falck et al. ${ }^{[7]}$ This group reported a synthesis of 14,15-epoxyeicosatrienoic acid from arachidonic acid (500 mg, 1.64 mmol) using CYP102A1 F87V (600 U, 500 nmol) and glucose-6-phosphate dehydrogenase for NADPH recycling. Their attempt was to dissolve the hydrophobic substrate using a large volume of aqueous buffer. $0.74 \mathrm{mmol}$ of product were obtained from 4 I reaction mixture, allowing calculation of a ttn of approximately 1500 . This demonstrates that the two-phase system, apart from advantages in reaction 
engineering, is a promising approach leading to a ttn of 12800 with cyclohexane and 30000 with myristic acid as substrate respectively. The total turnover number of the cofactor ranging from $\sim 300$ up to $\sim 1300$ is one of the highest reported to date for a preparative application of isolated oxygenases. The total turnover numbers for the biocatalyst exceed the value of up to 2867 reported for the asymmetric epoxidation of styrene by styrene monooxygenase (StyAB) in a two-phase dodecane / aqueous buffer system. ${ }^{[8]}$ In this case for the cofactor $\mathrm{NAD}^{+}$a maximum turnover number of 87 was detrmined. Lutz et al. investigated the preparative application of 2hydroxybiphenyl 3-monooxygenase with enzymatic cofactor regeneration. They reached a th for $\mathrm{NAD}^{+}$of maximally $503 \cdot{ }^{[53]}$ In cell-free application of cyclohexanone monooxygenase coupled to NADPH regeneration by alcohol dehydrogenase from Thermoanaerobium brockii it was shown that conversion of $10 \mathrm{~g} \mathrm{l}^{-1}$ bicyclo[3.2.0]hept2-en-6-one is possible if the substrate is fed continuously. ${ }^{[54]}$ While volumetric productivities reported here are quite low (maximum $0.15 \mathrm{~g} \mathrm{l}^{-1} \mathrm{~h}^{-1}$ ), higher values found in literature (up to $\left.1 \mathrm{~g} \mathrm{l}^{-1} \mathrm{~h}^{-1}\right)^{[8]}$ are usually calculated for reaction times of $10 \mathrm{~h}$ or less compared to up to $100 \mathrm{~h}$ in our P450-mediated approach.Switching the cofactor specificity of CYP102A1 to NADH allows to reduce the cofactor costs to about $20 \%$. Further investigations concerning the stability and general applicability of the $N A D^{+}$-dependent reaction system are required.

Essentially the results reported here suggest that use of cytochromes P450 in enzyme reactors is an emerging and practical method in fine chemical synthesis. The current state of our investigations reveals the following bottlenecks:

i) Low solubility of the hydrophobic substrates in aqueous buffer solution resulting in low overall reaction velocity.

ii) Insufficient stability and - of particular importance with cyclohexane and octane as substrates - activity of the monooxygenase under process conditions.

iii) In reactions with octane and myristic acid product mixtures were obtained. Further research in the field of catalyst design and reaction engineering is needed to optimise application of CYP102A1 in conversion of different substrates. In this context a detailed simulation of the processes under investigation will be advantageous. 
Comparison with other cofactor-dependent oxygenases reveals that cytochrome P450-monooxygenases act as candidates if biocatalysts performing selective oxidations are in demand.

\section{Experimental Section}

\section{Chemicals, Enzymes and Strains}

All chemical reagents were of analytical grade or higher and purchased from Fluka, Aldrich, Sigma or Riedel-de-Haën. NADPH tetrasodium salt and FDH from Pseudomonas sp 101 were procured from Jülich Fine Chemicals (Jülich, Germany). E. coli strain BL21 (DE3) and vector pET28a+ were obtained from Novagen (Madison, Wisconsin, USA).

Cyclohexane was distilled prior to use in order to remove traces of cyclohexanol and cyclohexanone.

Saturated solutions of substrates in aqueous buffer were prepared by adding $5 \mathrm{ml}$ of organic substrate to $50 \mathrm{ml}$ of $50 \mathrm{mM}$ potassium phosphate buffer (Kpi), $\mathrm{pH}$ 7.5. The biphasic mixture was vigorously stirred over night, the substrate-saturated aqueous phase was separated using a separatory funnel and used immediately.

\section{Design of NADH-dependent Reductase Mutants}

For creation of an NADH-dependent mutant of CYP102A1 a sequence alignment with the rat cytochrome $\mathrm{P} 450$ reductase was performed and two positions important for cofactor specificity of CYP102A1 were identified. The corresponding mutants were constructed by site-directed mutagenesis using the Stratagene QuickChange ${ }^{\mathrm{TM}}$ Kit (Stratagene, La Jolla, Ca, USA) according to the manufacturer's protocol. Mutations were introduced to plasmid pT-USC1BM ${ }^{[51]}$ using the following oligonucleotide primers:

Primer W1046S forward: 5'-gatacgcaaaagacgtgTCGgctgggtaagaattc-3'

Primer W1046S reverse: 5'-gaattcttacccagcCGAcacgtctttgcgtatc-3'

Primer W1046A forward: 5'-gatacgcaaaagacgtgGCGgctgggtaagaattc-3'

Primer W1046A reverse: 5'-gaattcttacccagcCGCcacgtctttgcgtatc-3'

Primer R966D forward: 5'-gcttcataccgcttttctGACatgccaaatcagccg-3' 
Primer R966D reverse: 5'-cggctgatttggcatGTCagaaaaagcggtatgaagc-3'

Reductase activity was measured by standard cytochrome c reduction assay as described previously. ${ }^{[50]}$

\section{Expression and Purification of CYP102A1 Mutants}

The expression system pET28a+CYP102A1 was described previously. ${ }^{[34]}$ Mutations were introduced by $\mathrm{PCR}$ using the QuikChange ${ }^{\mathrm{TM}}$ site-directed mutagenesis kit from Stratagene according to the manufacturer's protocol. ${ }^{[43]}$ High level protein expression was achieved using a slightly modified version of the protocol already published. ${ }^{[34]}$ By incubating the starter culture for only $4 \mathrm{~h}$, using terrific broth (TB)-medium for expression and prolonging cultivation time after induction to $16 \mathrm{~h}$ at $25^{\circ} \mathrm{C}, 800$ to $1200 \mathrm{nmol}$ (96 to $144 \mathrm{mg}$ ) of soluble CYP102A1 per litre of cell culture were obtained. Aliquots of the crude cell lysates containing 25 to $50 \mu \mathrm{M}$ CYP102A1 were stored at $-20^{\circ} \mathrm{C}$ or directly used for preparative reactions.

For kinetic measurements purified enzyme was used. Purification was performed according to a two-step strategy using a Ni-sepharose HP (Amersham Biosiences, Sweden) column with elution by $100 \mathrm{mM}$ imidazole first. For further purification and to remove imidazole, the eluate was loaded onto a fractogel EMD DEAE 650S (Merck KgaA, Darmstadt, Germany) column and eluted by applying a linear sodium chloride gradient.

\section{Activity Assays and Characterisation of Mutants}

Substrate binding difference spectra, NADPH oxidation and CO-difference spectra were recorded on an Ultrospec $3000 \mathrm{UV} / \mathrm{vis}$ spectrometer (Amersham Biosciences, Sweden). Concentration of correctly folded P450 enzymes was determined from the co-binding difference spectra of the reduced heme iron using an extinction coefficient of $91 \mathrm{mM}^{-1} \mathrm{~cm}^{-1}$ as reported elsewhere. ${ }^{[44]}$

For selection of mutants with activity towards cyclohexane $160 \mu \mathrm{l}$ cyclohexanesaturated $50 \mathrm{mM} \mathrm{KPi}, \mathrm{pH} 7.5 \quad(0.59 \mathrm{mM}$ cyclohexane) per well (96-well microtitreplate) was mixed with $20 \mu \mathrm{l}$ of cell lysate and the reaction was started by addition of $20 \mu \mathrm{l} 1 \mathrm{mM}$ NADPH stock solution in $50 \mathrm{mM} \mathrm{KPi}$. Reaction progress was 
monitored by measuring the absorption of NADPH at $340 \mathrm{~nm}$ for 5 minutes. For each mutant a blank containing no substrate was recorded and subtracted from the slope recorded in presence of substrate. Each of these measurements was repeated eight times and the average slope during the first $3 \mathrm{~min}$ of the reaction was calculated. For calculations of turnover numbers an extinction coefficient for NADPH of $6.22 \mathrm{mM}^{-1}$ $\mathrm{cm}^{-1}$ at $340 \mathrm{~nm}$ was used.

Kinetic measurements were performed in sealed cuvettes at least in triplicates to reduce standard errors.

Coupling efficiency was measured by incubation of purified CYP102A1 $(3 \mu \mathrm{M}), 50 \mathrm{U}$ $\mathrm{ml}^{-1}$ catalase with $0.4 \mathrm{mM}$ cyclohexane and $0.2 \mathrm{mM} \mathrm{NADPH}$ in a sealed cuvette. After total consumption of NADPH the reaction mixture was extracted three times with 300 $\mu \mathrm{l}$ 1-butanol or diethyl ether. The combined organic layers were dried over $\mathrm{MgSO}_{4}$ and analysed by quantitative GC/MS. From the amount of substrate converted, the coupling of NADPH oxidation to product formation can be deduced.

Substrate binding difference spectra were recorded using standard procedures. ${ }^{[13,45]}$ Myristic acid was oxidised in aqueous buffer by adding $20 \mu \mathrm{l}$ of $5 \mathrm{mM}$ myristic acid dissolved in DMSO to $930 \mu \mathrm{l}$ of $1 \mu \mathrm{M}$ CYP102A1 in $50 \mathrm{mM} \mathrm{KPi}, \mathrm{pH} 7.5$. The reaction was started by addition of $50 \mu \mathrm{l} 10 \mathrm{mM} \mathrm{NADPH}$ in $50 \mathrm{mM} \mathrm{KPi}, \mathrm{pH}$ 7.5. After $15 \mathrm{~min}$ the reaction mixture was acidified using dilute $\mathrm{HCl}$ and extracted thrice with diethyl ether and analysed as described in section product identification.

FDH activity assays were performed to estimate the stability of FDH when stirred with cyclohexane. The same assay was used during reactions to measure residual FDH activity. The assay was performed by adding $50 \mu \mathrm{FDH}$-containing solution to a cuvette containing $950 \mu \mathrm{l} \mathrm{FDH}$ reaction buffer $\left(50 \mathrm{mM} \mathrm{KPi}, 300 \mathrm{mM} \mathrm{Na}^{+} \mathrm{HCOO}^{-}, 0.1\right.$ $\mathrm{mM} \mathrm{NADP}^{+}, \mathrm{pH} 7.0$ ) and measuring NADPH development at $340 \mathrm{~nm}$.

\section{Preparative Incubation in Biphasic Systems}

The aqueous phase consisted of $250 \mathrm{mM}$ sodium formate, $50 \mathrm{mM} \mathrm{KPi}, 10 \mathrm{mg} \mathrm{ml}^{-1}$ BSA for stabilisation, $600 \mathrm{U} \mathrm{ml}^{-1}$ catalase to destroy traces of hydrogen peroxide, 0.1 $\mathrm{mM} \mathrm{NADP}{ }^{+}$. The initial activity of FDH in the reactions was calculated to exceed the initial activity of CYP102A1 in the respective reaction setup 1.5 -fold. Then the organic substrate was added. In case of cyclohexane and octane as substrates the distilled 
solvents were used as organic phase. In case of myristic acid conversion, the organic phase consisted of a $100 \mathrm{mM}$ solution of myristic acid in dodecane. Additionally $1 \%$ DMSO was added to the aqueous phase to enhance solubility of the organic substrate. To start the reactions the respective CYP102A1 mutant was added. For cyclohexane and octane conversions the amount of CYP102A1 added is given in the results section. Hydroxylation of myristic acid was performed by $100 \mathrm{nmol}$ CYP102A1 A74G, F87V, L188Q (NADPH dependent) and alternatively by $5 \mathrm{nmol}$ CYP102A1 A74G, F87V, L188Q, R966D, W1046S (NADH dependent).

For hydroxylation of cyclohexane in a Labfors 3 I fermenter (Infors AG, Bottmingen, Switzerland) the following parameters were used: $1.3 \mu \mathrm{mol}$ CYP102A1 R47L, Y51F, stirrer speed $350 \mathrm{rpm}$, aeration $0.5 \mathrm{I} \mathrm{min}^{-1}$ and readjustment of $\mathrm{pH}$ by $1 \mathrm{M} \mathrm{KPi}, 400$ $\mathrm{mM} \mathrm{Na}^{+} \mathrm{HCOO}^{-} \mathrm{pH}$ 6. The biphasic reaction emulsion consisted of $500 \mathrm{ml}$ of aqueous reaction phase and $500 \mathrm{ml}$ of cyclohexane. For online monitoring of the reaction parameters IRIS software was applied. To collect evaporated educt and product the fermenter was equipped with a cryo trap charged with dry ice. To prevent foam formation, $100 \mu$ l of antifoam (silicone oil) was added.

During the reaction course FDH activity assays were performed. When no activity could be detected any more, FDH was added (maximally once per reaction batch; half the amount of FDH as in the beginning of the reaction).

Monitoring of the reaction progress was achieved by taking samples from the organic phase, drying over $\mathrm{MgSO}_{4}$ and analysing by quantitative GC/MS. In case of myristic acid samples were taken from organic and aqueous phase (1:1), acidified by addition of dilute $\mathrm{HCl}$, extracted with diethyl ether and evaporated to dryness. Trimethylsilylation was achieved by dissolving the solid in N,Obis(trimethylsilyl)trifluoroacetamide and 1\% trimethylchlorosilane and incubation at $60^{\circ} \mathrm{C}$ for $30 \mathrm{~min}$ in a sealed vial.

For quantitative determination of total products, the reaction mixture was extracted three times with diethyl ether, dried and analysed by GC/MS. For cyclohexanol the phase partitioning between cyclohexane and the aqueous reaction medium was determined. Below $20 \mathrm{~g} \mathrm{I}^{-1}$ a linear relation of cyclohexanol in aqueous and organic phase was found:

[cyclohexanol in cyclohexane] $=(0.936+/-0.011)$ [cyclohexanol in aqueous phase] For myristic acid the acidified $(\mathrm{pH} 2)$ reaction mixture was extracted thrice with diethyl ether. The combined organic layers were evaporated in vacuo until only high-boiling 
dodecane was left. At this stage a white solid had formed. The solid was separated by centrifugation and washed twice with dodecane. Analysis of this solid revealed it consisted of $90 \%$ mono- and dihydroxy myristic acid. In contrast the dodecane phase contained $95 \%$ myristic acid and only traces of hydroxylated compounds.

\section{Product Identification}

Products were identified on a Shimadzu GC/MS-QP2010 equipped with a $30 \mathrm{~m}$ FSSupreme column (internal diameter $0.25 \mathrm{~mm}$, film thickness $0.25 \mu \mathrm{M}$ ) using helium as carrier gas at linear velocity of $30 \mathrm{~cm} \mathrm{~s}^{-1}$.

Cyclohexane: 1) $50^{\circ} \mathrm{C}$ for $\left.5 \mathrm{~min} 2\right) 50$ to $200^{\circ} \mathrm{C}$ at $20^{\circ} \mathrm{min}^{-1}$ 3) $2 \mathrm{~min}$ at $200^{\circ} \mathrm{C}$. The GC/MS signals of cyclohexane and cyclohexanol were calibrated for quantification using 10 standard concentrations ranging from 0.05 to $15 \mathrm{mM}$ and fitted to a quadratic function.

Octane: 1) $40^{\circ} \mathrm{C}$ for $1 \mathrm{~min}$ 2) 40 to $80^{\circ} \mathrm{C}$ at $2^{\circ} \mathrm{C} \mathrm{min}^{-1}$ 3) $1 \mathrm{~min}$ at $80^{\circ} \mathrm{C}$ 4) 80 to $200^{\circ} \mathrm{C}$

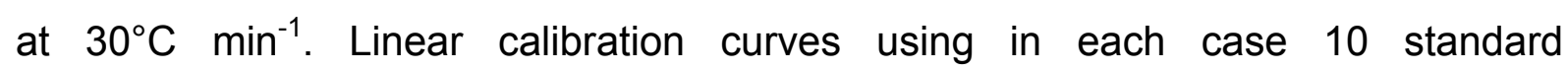
concentrations of 2-, 3- and 4-octanol and 2-, 3- and 4-octanone ranging from 0.01 to $1 \mathrm{mM}$ were created.

Myristic acid: 1) $175^{\circ} \mathrm{C}$ for $1 \mathrm{~min}$ 2) 175 to $275^{\circ} \mathrm{C}$ at $5^{\circ} \mathrm{C} \min ^{-1}$ 3) 1 min at $275^{\circ} \mathrm{C}$. Trimethylsilylated hydroxy derivatives of myristic acid were identified by their characteristic MS fragmentation patterns. 


\section{References}

[1] Cytochrome P450: Structure, Mechanism and Biochemistry; P. R. E. Ortiz de Montellano, Ed.; Plenum Press: New York, 1995.

[2] D. F. Lewis In Cytochromes P450 Structure, Function and Mechanism; Lewis, D. F., Ed.; Taylor and Francis Ltd.: London, 1996; pp 115-167.

[3] D. W. Nebert, F. J. Gonzalez, Annu. Rev. Biochem. 1987, 56, 945-993.

[4] K. Petzoldt, K. Annen, H. Laurent, R. Wiechert In US Patent; Schering Aktiengesellschaft (Berlin, Germany), 1982.

[5] S. Picataggio, T. Rohrer, K. Deanda, D. Lanning, R. Reynolds, J. Mielenz, L. D. Eirich, Biotechnology (N Y) 1992, 10, 894-898.

[6] V. Reipa, M. P. Mayhew, V. L. Vilker, Proc Natl Acad Sci U S A 1997, 94, 13554-13558.

[7] J. R. Falck, Y. K. Reddy, D. C. Haines, K. M. Reddy, U. M. Krishna, S. Graham, B. Murry, J. A. Peterson, Tetrahedron Lett. 2001, 42, 4131-4133.

[8] K. Hofstetter, J. Lutz, I. Lang, B. Witholt, A. Schmid, Angew. Chem. Int. Ed. Engl. 2004, 43, 2163-2166.

[9] V. B. Urlacher, S. Lutz-Wahl, R. D. Schmid, Appl. Microbiol. Biotechnol. 2004, 64, 317-325.

[10] V. Urlacher, R. D. Schmid, Curr. Opin. Biotechnol. 2002, 13, 557-564.

[11] L. O. Narhi, A. J. Fulco, J. Biol. Chem. 1986, 261, 7160-7169.

[12] L. P. Wen, A. J. Fulco, J. Biol. Chem. 1987, 262, 6676-6682.

[13] G. Truan, M. R. Komandla, J. R. Falck, J. A. Peterson, Arch. Biochem. Biophys. 1999, 366, 192-198.

[14] T. W. Ost, C. S. Miles, J. Murdoch, Y. Cheung, G. A. Reid, S. K. Chapman, A. W. Munro, FEBS Lett. 2000, 486, 173-177.

[15] O. Lentz, V. Urlacher, R. D. Schmid, J..Biotechnol. 2004, 108, 41-49.

[16] M. Budde, S. C. Maurer, R. D. Schmid, V. B. Urlacher, Appl..Microbiol. Biotechnol. 2004, 66, 180-186.

[17] M. C. Gustafsson, O. Roitel, K. R. Marshall, M. A. Noble, S. K. Chapman, A. Pessegueiro, A. J. Fulco, M. R. Cheesman, C. von Wachenfeldt, A. W. Munro, Biochemistry 2004, 43, 5474-5487.

[18] Q. S. Li, U. Schwaneberg, P. Fischer, R. D. Schmid, Chemistry 2000, 6, 15311536.

[19] D. Appel, S. Lutz-Wahl, P. Fischer, U. Schwaneberg, R. D. Schmid, J. Biotechnol. 2001, 88, 167-171.

[20] E. T. Farinas, U. Schwaneberg, A. Glieder, F. H. Arnold, Adv..Synth. Catal. 2001, 343, 601-606.

[21] O. Lentz, Q. S. Li, U. Schwaneberg, S. Lutz-Wahl, P. Fischer, R. D. Schmid, J. Mol. Cat. B 2001, 15, 123-133.

[22] Q. S. Li, J. Ogawa, R. D. Schmid, S. Shimizu, Appl. Environ. Microbiol. 2001, 67, 5735-5739.

[23] Q. S. Li, J. Ogawa, R. D. Schmid, S. Shimizu, FEBS Lett. 2001, 508, 249-252.

[24] A. Glieder, E. T. Farinas, F. H. Arnold, Nat. Biotechnol. 2002, 20, 1135-9.

[25] M. W. Peters, P. Meinhold, A. Glieder, F. H. Arnold, J. Am. Chem. Soc. 2003, $125,13442-13450$.

[26] T. Seng Wong, F. H. Arnold, U. Schwaneberg, Biotechnol. Bioeng. 2004, 85, 351-358.

[27] S. Schneider, M. G. Wubbolts, G. Oesterhelt, D. Sanglard, B. Witholt, Biotechnol. Bioeng. 1999, 64, 333-341.

[28] P. C. Cirino, F. H. Arnold, Angew. Chem. Int. Ed. Engl. 2003, 42, 3299-3301. 
[29] R. W. Estabrook, M. S. Shet, K. Faulkner, C. W. Fisher, Endocr. Res. 1996, 22, 665-671.

[30] B. D. Fleming, Y. Tian, S. G. Bell, L. L. Wong, V. Urlacher, H. A. Hill, Eur. J. Biochem. 2003, 270, 4082-8.

[31] A. K. Udit, F. H. Arnold, H. B. Gray, J. Inorg. Biochem. 2004, 98, 1547-1550.

[32] F. Hollmann, B. Witholt, A. Schmid, J. Mol. Cat. B 2002, 791, 1-10.

[33] S. B. Lamb, D. C. Lamb, S. L. Kelly, D. C. Stuckey, FEBS Lett. 1998, 431, 343-346.

[34] S. Maurer, V. Urlacher, H. Schulze, R. D. Schmid, Adv. Synth. Catal. 2003, 345, 802-810.

[35] H. Li, T. L. Poulos, Nat. Struct. Biol. 1997, 4, 140-146.

[36] M. A. Noble, C. S. Miles, S. K. Chapman, D. A. Lysek, A. C. MacKay, G. A. Reid, R. P. Hanzlik, A. W. Munro, Biochem. J. 1999, 339, 371-379.

[37] A. B. Carmichael, L. L. Wong, Eur. J. Biochem. 2001, 268, 3117-3125.

[38] Q. S. Li, U. Schwaneberg, M. Fischer, J. Schmitt, J. Pleiss, S. Lutz-Wahl, R. D. Schmid, Biochim. Biophys. Acta. 2001, 1545, 114-121.

[39] L. D. Gorsky, D. R. Koop, M. J. Coon, J. Biol. Chem. 1984, 259, 6812-7.

[40] A. B. Carmichael, L. L. Wong, Eur. J. Biochem. 2001, 268, 3117-25.

[41] V. I. Tishkov, A. G. Galkin, V. V. Fedorchuk, P. A. Savitsky, A. M. Rojkova, H. Gieren, M. R. Kula, Biotechnol. Bioeng. 1999, 64, 187-193.

[42] F. Ahmed, E. H. Al-Mutairi, K. L. Avery, P. M. Cullis, W. U. Primrose, G. C. K. Roberts, C. L. Willis, Chemical Communications 1999, 2049-2050.

[43] M. A. Vandeyar, M. P. Weiner, C. J. Hutton, C. A. Batt, Gene 1988, 65, 129133.

[44] T. Omura, R. J. Sato, J. Biol. Chem. 1964, 239, 2370-2378.

[45] K. C. Leibman, A. G. Hildebrandt, R. W. Estabrook, Biochem. Biophys. Res. Commun. 1969, 36, 789-794.

[46] V. I. Tishkov, A. G. Galkin, G. N. Marchenko, O. A. Egorova, D. V. Sheluho, L. B. Kulakova, L. A. Dementieva, A. M. Egorov, Biochem. Biophys. Res. Commun. 1993, 192, 976-981.

[47] J. T. Wu, L. H. Wu, J. A. Knigh, Clin. Chem. 1986, 32, 314-319.

[48] C.L. Elmore, T. Porter, J. Biol. Chem. 2002, 50, 48960-48964.

[49] O. Döhr, M. J. I. Paine, T. Friedberg, G. C. K. Roberts, C. R. Wolf, Proc. Natl. Acad. Sci. USA, 2001, 98, 81-86.

[50] A. H. Phillips, R. G. Langdon, J. Biol. Chem. 1962, 237, 2652-2660.

[51] U. Schwaneberg, A. Sprauer, C. Schmidt-Dannert, R. D. Schmid, J. Chromatogr. 1999, 848, 149-159.

[52] L. A. Kaysser, S. Eiben, R. D. Schmid, V. B. Urlacher, in preparation.

[53] F. Zambiachini, P. Pasta, G. Carrea, S. Colonna, N. Gaggero, J. M. Woodley, Biotechnol. Bioeng. 2002, 78, 489-496.

[54] J. Lutz, V. V. Mozhaev, Y. L. Khmelnitsky, B. Witholt, A. Schmid, 2002, J. Mol. Catal. B: Enzymatic. 2002, 19-20, 177-187. 